\title{
Impact and Improvement of Technological Infrastructure Services in The Health Sector
}

\author{
Mayra Victoria Lizcano López ${ }^{1}$, Laura Beatriz Vidal Turrubiates², Eloisa Mendoza \\ Vázquez ${ }^{3}$ \\ Universidad Juárez Autonoma de Tabasco. From the Academic Division of Computing and \\ Systems. In the state of Tabasco, Mexico ${ }^{1,2,3}$
}

\begin{abstract}
Nowadays, due to the development and scope of information technology (IT), both public and private health institutions have been seeing great changes as a basis in the development of citizen care activities. Talking about the health sector and the strategic changes in IT, is talking about a reorganization that breaks the model of a compacted organizational culture, to promote new growth strategies offering quality services to the community.

Today, technology and innovation in healthcare units are essential, facing major challenges that arise in developing sustainable health systems, all aimed at achieving the basic elements such as quality, safety and universal coverage, where the key pieces for to achieve it are innovation and updating.

IT advances at great speed, raising the disposition of all potential, where its usefulness in the health units guarantees the improvement of hospital administration, bringing great benefits for the sector. This research presents a proposal of solid IT infrastructure for the Center for Health of Expanded Services (CESSA) Dr. Maximiliano Dorantes, Villahermosa Tabasco, for the configuration of networks, improvement of processes and services of citizen attention, in addition to achieving security of patient information through electronic clinical systems as an improvement in IT services. Likewise, it allows enabling new technologies, which makes it indispensable to offer IT services and deliver reliable results to end users.
\end{abstract}

Keywords: Health sector; hospitals; information technology; innovation; technological infrastructure.

\section{Introduction}

Health institutions in Mexico need to project more towards technology and the new resources that it offers. Technology is fundamental to share patient information, and to serve them better by reducing the possibilities of human error. (Manzano, 2014)

In the beginning, typewriters were essential material and instrument in all areas of the health 


\section{INTERNATIONAL CONFERENCE ON BUSINESS, MANAGEMENT AND FINANCE}

\section{UNITED KINGDOM | LONDON | March 7-9,2019}

sector, their use went from the hand of a social worker to issuing a medical prescription typed by a doctor inside a hospital. Module or an office.

And what about the files of the patients, those long and extensive hours of search, folder by folder, name by name where by minimum we spent 10 to 15 minutes to find the requested file. But behind a need there is a new solution; that is why, over time, the presence of IT in hospitals has become an indispensable part, because thanks to their support, changes have arisen that have evolved and lead us to grow both as people and as a sector. The change does not come by itself, but by deciding to go further, that is, to accept leaving our compacted organizational culture and modify the way of organizing and carrying out the work. Today we have to take the decision to take the sector to new opportunities and what better than to achieve it with the support of information technologies

On the other hand, it is not enough to have trained personnel in the area, but also with a solid infrastructure through which IT services can be offered in the institution, this in order to minimize costs, time, efforts, and streamline the response time expected by the end user.

Currently, the health industry has evolved and today is not only to serve patients in real time, but to transform itself with the help of information technologies, leading the health sector to obtain fast and reliable results that support, at all times and at all times, the health care, contemplating from the diagnosis and the whole process of the patient's follow-up, from the time of admission to hospital to discharge.

Today, more than ever, Latin America is at a great crossroads, with the different players in the health sector facing great challenges to develop sustainable health systems.

According to Ángel Vázquez Hernández, CEO of Livemed and ExpoMED México 2018 "and we are not worried about achieving equity in terms of health in the region" and adds "On the contrary, strategies are being promoted to make the health sector evolve and achieve greater and better access to it, and the Sustainable Health Agenda for the Americas is a clear example of this. "

The health sector in Mexico faces a panorama of major political and socioeconomic changes to improve and increase the access of health services to the population,

which translates into the development of a new hospital infrastructure and the need for technology tools of information with sufficient quality in their data to plan a correct strategy in the development of salud.es reality that innovation and new technologies provide different growth opportunities to any sector, and the health sector is not the exception, only the production of medical devices in Mexico reaches a value of 15.220 million dollars placing it as the largest market in Latin America and for 2020, it is expected that the industry behind the innovation and development of new medical devices in Mexico, grow with an estimated of 5.2 percentage points

Innovation has a lot of inclusion in the sector, especially if the use of technology as a facilitator in the exchange, management and control of information between patients and 


\section{INTERNATIONAL CONFERENCE ON BUSINESS, MANAGEMENT AND FINANCE}

\section{UNITED KINGDOM | LONDON | March 7-9,2019}

medical personnel is considered.

As the issue of a technological infrastructure becomes the central issue for the implementation and operation of new technologies, it is required that the hospital has a robust network infrastructure that supports the requirements of innovative applications, taking into account that the The presence of advances in technology has led patients to demand better facilities, state-of-the-art medical equipment, and quality treatment from the staff working in the health institution, coupled with this as a result of these developments. managers and directors of hospitals or health centers invest in facilities and technologies that provide these facilities.

According to the Ministry of Health, this technological evolution will increase productivity by $20 \%$; Reduce by $60 \%$ the times and days of waiting to receive consultation; savings of up to $80 \%$ in stationery; reduce the programming times of surgeries, which can be up to 62 days; as well as reducing the waste of medication, are adoptions that hospitals and health centers see as allies for improvements in all services. (Staff, 2017)

In the majority of health centers, computers have been used for basic tasks, such as administrative tasks that are the daily tasks, where basic services are used, such as: electronic mail, to send and receive information through a e-mail or Website, which is the route through which we can access and learn more about the services offered by the hospital and communication in real time, through a social network in a delicate space especially for this or maintaining communication with an operator.

The technological evolution in the use of electronic medical records will allow productivity to grow by $20 \%$, reduce by $60 \%$ the waiting times and days to receive consultation, save up to $80 \%$ in stationery: reduce the time of programming surgeries, in addition to placing Mexico and Latin America at the height of other countries.

To make use of information technologies in the health sector, there are systems that automate processes and provide quality patient care, improve the quality of the network infrastructure, reduce risks, optimize response time, promote the processes and services for the desired purposes.

Information technology is the key to share and exchange patient information, and the staff that works in hospital to provide quality care, while reducing the chances of human error.

So it is important to have comprehensive health infrastructure planning schemes that include and align the requirements under equipment, human resources, maintenance and operation, to monitor systems, optimizing the delivery time of information in the areas of work, with safe and reliable electronic clinical records, where the doctor responsible for the patient takes orderly detailed control of the aspects relating to the patient's health. On the other hand, it is essential to have the precise administration of database services to keep track of services, avoiding future failures

Some of the health IT systems already adopted by some hospitals are: 


\section{INTERNATIONAL CONFERENCE ON BUSINESS, MANAGEMENT AND FINANCE}

\section{UNITED KINGDOM | LONDON | March 7-9,2019}

1. Administrative - hospital: Such as billing, word processors, web portal and email. Following with the Administrative - Clinical: that are systems that offer the management of appointment schedules, reminders, admissions of patients, insurance information, institutional management systems and medical equipment.

2. Direct clinical support: Prescriptions, medication administration, storage and recovery of images. Laboratory exams.

3. More advanced systems: electronic clinical histories, semi-automated drug administration, real-time location systems, decision support systems, access at the point of care of the provider and interoperability of multiple systems. All work together and focused to support patient care (Sherman, 2015)

\section{Methods}

1.- The research method is a qualitative approach, with data collection techniques such as depth interviews, group meetings applying the Brainstorming technique to obtain portraits from a group of experts in the field.

2.-IT technology infrastructure methodology is developed based on the 4-layer IT service management model, is the foundation for the development of applied research.

The models under which the IT technological infrastructure is developed, is a process-based discipline which focuses on aligning the services provided with the needs of the companies, emphasizing the benefits that the final client receives.

The task of IT management to manage, correctly monitor resources as well as direct strategies for the management of an organization, infrastructure, IT processes. Having the correct alignment manages and constitutes criteria, ethical, cultural, including laws, mission, vision, roles and policies inside and outside the company.

So the mobile of the technological structure is the coordinated work in a technological field to identify and prioritize the technological needs of research, through the operation and monitoring center, we verify the function of the systems to show their efficiency and functioning of the applications avoiding possible problems and interruptions in the operation.

The IT process management coordinates the work and at the same time the resources of the organization in order to provide answers in a timely manner in time and form to the end user. The contact center is the access bridge to the institution, interacting via the web, by e-mail, by telephone and even going to the health center.

Its importance lies in carrying out good service management, providing a series of benefits, with the main objective of aligning IT with the business and meeting the demands of customer needs in a better way, in addition to improving the quality of services of IT, which takes into account the company's needs

\section{Results}




\section{INTERNATIONAL CONFERENCE ON BUSINESS, MANAGEMENT AND FINANCE}

\section{UNITED KINGDOM | LONDON | March 7-9,2019}

The cause of the problems in the hospital units was identified, and as a proposal, the 4-layer IT service management model was exposed. To obtain the final result Improve the quality of the network infrastructure established in the health units and improve the quality of the services of the IT infrastructure. Information technologies have made it possible to improve clinical collaboration because health personnel and doctors now have easier access to patients' medical records. All users share the same information in this way has improved patient service.

\section{References}

Boletin, S. (2017). Sector salud demanda infraestructura robusta: Panduit. Seguridad de TIe infraestructura. Recuperado de: https://seguridadti.mx/redes-e-infraestructuraboletin/item/2051-infraestructura-fisica-robusta-para-sumarse-agilmente-a-tendencias-comoe-health-y-m-health/2051-infraestructura-fisica-robusta-para-sumarse-agilmente-atendencias-como-e-health-y-m-health

Gallardo, L. (2017) ¿Cuáles son los beneficios de la implementación de software de gestión de servicios. DeMenteInt. Recuperado de: http://dementeint.blogspot.com/2017/07/cuales-sonlos-beneficios-de-la.html

Informacion, d. G. (2011). Manual del Expediente Clinico Electronico de Información en Salud. México, D.F.

Manzano, A. (2017), infraestructura para la salud con tecnología. Forbes. Recuperado de: https://www.forbes.com.mx/infraestructura-para-la-salud-con-tecnologia/

Sherman, P. R. (2015). ¿Porque usar tecnologias de informacion (TI) en los hospitales. el hospital.Recuperadode:http://www.elhospital.com/blogs/Por-que-usar-tecnologias-deinformacion-TI-en-los-hospitales+107259

Top Management. (2018). Grandes desigualdades en el sector salud de Latinoamérica.

Recuperado de: http://topmanagement.com.mx/grandes-desigualdades-sector-saludlatinoamerica/ 